\title{
EFEITOS DO ALAGAMENTO DO SUBSTRATO NO CRESCIMENTO E NA COMPOSIÇÃO QUÍMICA DE GENÓTIPOS CLONAIS DE Theobroma cacao L. ${ }^{1}$
}

\author{
BRUNA CARMO REHEM ${ }^{2}$, ALEX-ALAN FURTADO DE ALMEIDA², \\ MARCELO SCHRAMM MIELKE ${ }^{4}$, FÁBIO PINTO GOMES ${ }^{2}$
}

RESUMO-O alagamento do solo pode promover alterações no metabolismo celular e causar desvios nas condições ótimas de crescimento das plantas, gerando uma condição de estresse. Objetivou-se no presente trabalho avaliar os efeitos do alagamento no crescimento e na nutrição mineral de seis clones de $T$. cacao (CP-49, CCN-10, CP-06, CEPEC-2007, CEPEC-2008 e PS-1319), para elucidar possíveis mecanismos de tolerância ao alagamento. Mudas clonais de T. cacao, com 6 meses de idade, foram submetidas ao alagamento, juntamente com o tratamento-controle (não alagado), por 30 dias. Observou-se, no final desse período, que o alagamento promoveu diminuição nas taxas de crescimento relativo radicular (exceto para CP-06) e de área foliar, acúmulo de matéria seca e incremento nas taxas de crescimento relativo caulinar (exceto para os clones CP-06 e CEPEC-2008) e assimilatória líquida (exceto para o clone alagado PS-1319) e de massa foliar específica para os clones CP-49, CCN-10 e CP-06. Os clones que sobreviveram aos 30 dias de alagamento apresentaram baixos valores de razão de área foliar. De modo geral, o alagamento do substrato acarretou deficiência na absorção de macro e micronutrientes minerais, exceto de Fe. Dentre os clones avaliados, o CP-49 foi tolerante e o CEPEC-2008 não tolerante ao alagamento. Os demais clones ficaram numa posição intermediária. Logo, o clone CP-49 tem grande potencial para ser cultivado em condições de alagamento. Termos para indexação: anoxia, cacau, crescimento vegetativo, estresse abiótico, nutrição de plantas.

\section{EFFECTS OF SUBSTRATE FLOODING ON GROWTH AND CHEMICAL COMPOSITION OF Theobroma cacao L. CLONAL GENOTYPES}

\begin{abstract}
Soil flooding can induce changes in cell metabolism and cause deviations in optimum conditions for plant growth, creating a stress condition. The objective of this work was to evaluate the effects of flooding on growth and mineral nutrition of six T. cacao clones (CP-49, CCN-10, CP-06, CEPEC-2007, CEPEC-2008 and PS-1319), aiming to clarify the possible mechanisms of soil flooding tolerance. Plants of T. cacao with 6 months of age were subject to soil flooding, along with the control treatment (not flooded), for 30 days. At the end of the experiment, flooding induced decreases in the root growth rates (except for CP-06) and leaf area, increases in the dry mass, in the stem relative growth rate (except for the clones CP06 and CEPEC-2008), in the net assimilation rates (except for PS-1319) and in the specific leaf mass of the clones CP-49, CCN-10 and CP-06. Plants that survived the 30 days of flooding also presented low values of the leaf area ratio. In general, substrate flooding has caused disability in the absorption of macro and micro nutrients, with exception for Fe. Among all clones evaluated, CP-49 was considered as tolerant and CEPEC-2008 as non-tolerant to soil flooding. The other clones are in an intermediate position. Therefore, the clone $\mathrm{CP}-49$ presents a great potential to be cultivated in flood prone environments.
\end{abstract}

Index terms: anoxia, cocoa, plant growth, abiotic stress, plant nutrition. 


\section{INTRODUÇÃO}

A indução de condições de hipoxia ou anoxia em torno do sistema radicular aumenta os efeitos adversos do alagamento (Dennis et al., 2000). A tolerância a estresses anaeróbios pode variar a depender das espécies, dos órgãos diretamente afetados, do estágio de desenvolvimento e das condições externas (Vartapetian e Jackson, 1997). Respostas das plantas ao alagamento podem incluir senescência foliar prematura, diminuição do volume de raízes e do crescimento da parte aérea, formação de raízes adventícias, aerênquima e lenticelas hipertróficas (Almeida e Valle, 2007). A diminuição da disponibilidade de $\mathrm{O}_{2}$ no solo, em ecossistemas alagadiços, influencia na sobrevivência, no crescimento e na produtividade das plantas terrestres (Pezeshki, 2001), interferindo nas trocas gasosas foliares, na absorção de macro e micronutrientes minerais, no balanço hormonal (Kozlowski et al., 1991), na partição e translocação de fotoassimilados e na produção de biomassa (Pezeshki, 2001), entre outras respostas morfofisiológicas.

Utiliza-se a análise quantitativa de crescimento para avaliar os efeitos de fatores ambientais no crescimento e desenvolvimento de espécies de determinada comunidade vegetal e comparar o crescimento entre espécies típicas de diferentes ecossistemas (Chiariello et al., 1989; Hunt, 1990). O crescimento das plantas e a produtividade primária dos ecossistemas são, em última instância, dependentes da fotossíntese (Pereira, 1995). Qualquer fator estressante do ambiente que, de alguma forma, afete a taxa fotossintética, irá interferir no ganho líquido de matéria seca e, consequentemente, no crescimento (Pereira, 1995). Portanto, os estudos que avaliem ao longo de um período os efeitos do estresse sobre os parâmetros de crescimento e a alocação de fotoassimilados, auxiliam na elucidação dos mecanismos de tolerância ao estresse, particularmente, nas espécies que alteram os padrões de crescimento quando submetidas a condições ambientais extremas.

Para o cultivo de cacaueiro (Theobroma cacao) em condições de alagamento, testou-se a hipótese da existência de variabilidade intergenotípica para este tipo de estresse abiótico, por se tratar de uma espécie alógama, cujo centro de origem apresenta clima tropical úmido. Portanto, o presente trabalho teve como objetivo principal avaliar as respostas do crescimento e da nutrição mineral de clones de cacau ao alagamento do substrato.

\section{MATERIAIS E MÉTODOS}

\section{Material vegetal e condições de cultivo}

$\mathrm{O}$ material utilizado neste experimento foi os clones de cacaueiro (Theobroma cacao L.) CCN10, CP-49, CP-06, CEPEC-2007, CEPEC-2008 e PS-1319, de alta produtividade e resistentes a Moniliophthora perniciosa, agente causal da vassoura-de-bruxa. O material foi propagado no Instituto Biofábrica de Cacau (IBC), localizado no distrito do Banco do Pedro, Ilhéus-BA, por enraizamento de estacas com aproximadamente 16 $\mathrm{cm}$ de comprimento, retiradas de extremidades de ramos plagiotrópicos de plantas- matrizes com 5 a 10 anos de idade, e as folhas foram cortadas e reduzidas a $75 \%$, em 15-02-2007.

Utilizou-se ácido indol-3-butírico $\left(4 \mathrm{~g} \mathrm{~kg}^{-1}\right)$ diluído em talco, na base das estacas, como indutor da formação de raízes adventícias no momento do estaqueamento em tubetes plásticos pretos com capacidade de $288 \mathrm{dm}^{3}$.Durante a produção dessas mudas, foi seguido o protocolo da Biofábrica. Os tubetes foram preenchidos com turfa + cascas de Pinnus misturada, na proporção de 1:1, com fibra de coco. Também foram colocados macro e micronutrientes de acordo com as exigências da cultura (Souza Júnior, 2007). Após o estaqueamento, os tubetes, colocados em bandejas plásticas com capacidade para 54 unidades, foram transportados para viveiro coberto por telas plásticas pretas com $50 \%$ de sombra. O sistema de irrigação foi por microaspersão, com vazão de $40 \mathrm{~L} / \mathrm{h}$, acionado a cada cinco minutos por 30 segundos, nos primeiros 60 dias, e a cada 10 minutos por 30 segundos até o quarto mês.

No quarto mês (15-06-2007) após o estaqueamento, época em que as estacas já estavam enraizadas e já emitiam novos ramos e folhas, as mudas foram transplantadas para sacos plásticos com capacidade de $3 \mathrm{~L}$, contendo o mesmo substrato de enraizamento. Posteriormente, as mudas foram transportadas para a casa de vegetação da UESC (14 48 $53^{\prime}$ ” S / $\left.39^{\circ} 02^{\prime} 01^{\prime \prime} \mathrm{W}\right)$, onde permaneceram por dois meses para crescimento e aclimatação. Seis meses após o estaqueamento (15-08-2007), iniciaram-se as avaliações dos efeitos do alagamento do substrato sobre suas características fisiológicas. O alagamento foi obtido colocando-se quatro mudas de cada clone em baldes plásticos com capacidade de $20 \mathrm{~L}$, e adicionandos $10 \mathrm{~L}$ de água (condutividade elétrica de $160,6 \mu \mathrm{S} \mathrm{cm}^{-1}$ a $27,2{ }^{\circ} \mathrm{C}$ ), de modo que o seu nível permanecesse $2 \mathrm{~cm}$ acima do substrato (tratamento alagado), cujo volume foi mantido 
constante pela reposição de água por um período de 30 dias. No tratamento- controle, as mudas clonais foram colocadas em baldes com a mesma capacidade, mas com fundos perfurados para escoamento do excesso de água de irrigação.

\section{Variáveis de Crescimento}

As mudas clonais, submetidas aos dois regimes hídricos foram coletadas no momento da aplicação dos tratamentos e aos 30 dias de alagamento. Durante as coletas, as mudas foram divididas em raiz, caule e folha, e, em seguida, após a medição de área foliar total, foram armazenadas isoladamente em sacos de papel e colocadas para secar em estufa de circulação forçada de ar, a $75^{\circ} \mathrm{C}$, até massa constante, para a obtenção da biomassa seca total da planta e de suas partes. A área foliar foi mensurada com um medidor de área foliar LI-3100 (Li-Cor, inc. Lincoln, Nebraska, USA).

A partir da biomassa seca das diferentes partes e de suas respectivas áreas foliares, foram determinados: acúmulo de matéria seca total (AMS), taxas de crescimento relativo (TCR) e assimilatória líquida (TAL), massa foliar específica (MFE) e razão de área foliar (RAF) (Radford, 1967; Richards, 1969; Hunt, 1990) de cada clone.

\section{Composição Química}

$\mathrm{Na}$ biomassa seca das diversas partes, foram analisados os teores de alguns macro e micronutrientes minerais. Após digestão nitroperclórica, a determinação dos teores de $\mathrm{Ca}, \mathrm{Mg}$, $\mathrm{Fe}, \mathrm{Zn}, \mathrm{Cu}$ e $\mathrm{Mn}$ foi efetuada por espectrofotometria de absorção atômica; P por colorimetria utilizando o método da vitamina C (Braga e Defelipo, 1974) e $\mathrm{K}$ por fotometria de emissão de chama (Isaac e Kerber, 1971). O N foi determinado pelo método de Kjeldahl após digestão sulfussalicílica das amostras (Golterman et al., 1978).

\section{Análise Estatística}

$\mathrm{O}$ delineamento experimental utilizado foi o inteiramente casualizado, com 12 tratamentos (seis clones e aos dois regimes hídricos), cinco repetições e quatro plantas por unidade experimental. Os resultados experimentais foram submetidos à análise de variância (ANOVA). Fizeram-se comparações entre as médias dos tratamentos alagado, e o controle por meio do teste $t$.

\section{RESULTADOS}

Todos os clones avaliados sobreviveram aos 30 dias de alagamento (DAL). Durante este período, observaram-se sintomas de estresse por hipoxia, como clorose de folhas maduras, decréscimo na formação de folhas, senescência foliar, desenvolvimento de lenticelas hipertróficas e formação de raízes adventícias na base do caule e nas raízes adventícias preexistentes (dados não mostrados). Estes mesmos sintomas foram observados por Sena Gomes e Kozlowski (1986) em plântulas de cacaueiro 'Catongo', durante 60 dias de alagamento do substrato contendo uma mistura de argila, areia e vermiculita, na proporção de 2:1:1.

No final do período experimental, verificouse uma tendência de decréscimo nos valores das taxas de crescimento relativo radicular (TCRR) e foliar (TCRF) para a maioria dos clones avaliados, à exceção de PS-1319, cujos valores de TCRF aumentaram, e CP-06, que permaneceram constantes para TCRR (Figs. 1A e 1C, respectivamente). Os valores de TCRR evidenciam que, com exceção do CP-06, os demais clones foram influenciados significativamente, sendo os clones CCN-10 e PS1319 os mais afetados pelo alagamento em relação a esta variável.

Para TCRF, os clones CCN-10, CP-06 e CEPEC-2008 foram afetados superficialmente. Desses, o CCN-10 apresentou menor diminuição, e o CP-06, a maior com relação ao controle. Por outro lado, observou-se uma diminuição nos valores da taxa de crescimento relativo caulinar (TCRC) somente para o clone alagado CP-06 (Fig. 1B). Para este parâmetro, os clones CEPEC-2007, CEPEC-2008 e PS-1319 foram aqueles que exibiram os maiores valores, ao passo que os menores valores foram encontrados em CCN-10. Verificou-se uma tendência de diminuição nos valores de TCRAF para todos os clones avaliados (Fig. 1D). Resultados semelhantes foram observados também por Sena Gomes e Kozlowski (1986) trabalhando com plântulas de T.cacao var. 'Catongo' alagadas.

Observou-se, durante o período experimental, que o alagamento do substrato promoveu decréscimos significativos $(\mathrm{P}<0,01$ e $\mathrm{P}<0,05)$ nos valores da taxa assimilatória líquida (TAL) para a maioria dos clones avaliados, exceto para PS-1319 (Fig. 2A). Os maiores valores de TAL foram observados em CEPEC-2008 e PS-1319, enquanto o clone CEPEC-2007 apresentou os menores valores. Em contrapartida, houve diminuições significativas $(\mathrm{P}<0,01$ e $\mathrm{P}<0,10)$ nos valores de acúmulo de matéria seca (AMS) para a maioria dos clones analisados (Fig. 2B). Para a AMS, os clones que apresentaram os maiores valores foram CEPEC-2008 e PS-1319, tanto para o tratamentocontrole quanto para o alagado, enquanto o $\mathrm{CCN}-10$ apresentou o valor mais baixo para o alagado. 
Neste mesmo período, constatou-se que o alagamento também promoveu incremento nos valores de massa foliar específica (MFE) para a maioria dos clones avaliados, à exceção de CP-06 e CEPEC-2007 (Fig. 2C). Por outro lado, verificouse uma diminuição significativa $(\mathrm{P}<0,01, \mathrm{P}<0,05$ e $\mathrm{P}<0,10)$ nos valores da razão de área foliar (RAF) para a maioria dos clones alagados, à exceção de CP-06 e CEPEC-2007 (Fig. 2D).

De modo geral, o alagamento do substrato promoveu diminuição na absorção de N, P, K, Ca e $\mathrm{Mg}$ nos clones avaliados. Observaram-se, em todos os órgãos vegetativos, decréscimos nos teores de $\mathrm{N}$ para CP-49, CEPEC-2008 e PS-1319 (Fig. 3A) e de $\mathrm{P}$ para todos os clones estudados (Fig. 3B). Além disso, houve também decréscimos significativos $(\mathrm{P}<0,01)$ em todas as partes da planta nos teores de K, para os clones CCN-10, CEPEC-2007 e CEPEC-2008 (Fig. 3C), e de Ca para CCN-10, CP-06 e CEPEC-2008 (Fig. 3D); ao passo que decréscimos significativos $(\mathrm{P}<0,01)$ de $\mathrm{Mg}$ em todas as partes da planta foram observados somente para os clones CP-06 e CEPEC-2008, quando comparados com os seus respectivos controles (Fig. 3E).

$\mathrm{O}$ alagamento também promoveu mudanças nos teores de micronutrientes nos clones avaliados. Ao final do período experimental, a maioria dos clones alagados apresentou tendência de aumento no teor de Fe nas raízes e no caule, exceto para os clones $\mathrm{CP}-49$, que apresentaram decréscimo de Fe no caule e CEPEC-2008, que foi marcado por exibir diminuição do teor deste micronutriente na raiz (Fig. 4A). Entretanto, para os clones CEPEC-2007, CEPEC-2008 e PS-1319, houve uma diminuição na disponibilidade de $\mathrm{Zn}$ no caule e nas folhas, ao passo que para $\mathrm{CCN}-10$ e CP-49 observou-se decréscimos deste elemento nas raízes e no caule, enquanto em CP-06 se verificou um declínio nas raízes e folhas (Fig. 4B). Por outro lado, constatou-se diminuição no teor de $\mathrm{Cu}$ no caule para os clones alagados $\mathrm{CCN}$ 10, CP-49, CEPEC-2007 e CEPEC-2008, e aumento nas folhas para $\mathrm{CCN}-10$ e $\mathrm{CP}-49$ e nas raízes para CP-49, CEPEC-2007, CEPEC-2008 e PS-1319 (Fig. 4C). Além disso, os decréscimos significativos $(\mathrm{P}<0,01)$ no teor de $\mathrm{Mn}$ em todas as partes da planta toda foram observados somente para os clones CP49, CP-06, CEPEC-2007 e CEPEC-2008, quando comparados aos seus respectivos controles (Fig. 4D).

\section{DISCUSSÃO}

Períodos longos de alagamento normalmente resultam na paralisação do crescimento da parte aérea e radicular, murcha foliar, decréscimo na absorção de nutrientes, efeitos estes que, na maioria das vezes, podem levar à morte da planta (Schaffer et al., 1992). Segundo Ishida et al. (2002), em várias espécies vegetais, o decréscimo no crescimento torna-se tão intenso, podendo promover danos irreversíveis que não permitem a retomada do crescimento após a drenagem da água. A manutenção do crescimento em condições de anoxia do solo depende do estado nutricional das plantas (Santiago e Paoli, 2003) e de outros fatores normalmente associados às respostas de crescimento, como o nível da água acima do solo e o tempo de duração do alagamento (Parolin, 2001). A clorose promovida nas folhas dos clones de T. cacao pelo alagamento pode ter sido acentuada pelo decréscimo do teor de nutrientes minerais do substrato, em função do longo período de alagamento (Ishida et al., 2002)

A variação nos valores de taxa de crescimento relativo reflete de modo claro o efeito do estresse hídrico no acúmulo de matéria seca total (Chiariello et al., 1991), como observado nos resultados deste trabalho. O crescimento da parte aérea de mudas ou enxertos arbóreos geralmente decresce em resposta ao alagamento (Núñez-Elisea et al., 1999), promovendo a diminuição nos valores de TCRF, como foi verificado para os clones avaliados, exceto para PS-1319 (Fig. 1A). A capacidade de manutenção do crescimento em altura sob condições de alagamento pode ser fundamental para a sobrevivência da planta, sobretudo se representar a fuga da submersão total (Santiago e Paoli, 2003). Segundo Shaffer et al. (1992), as diminuições de TCRR, TCRF e de TCRAF, como foi observado para a maioria dos clones estudados (Figs. 1A, 1C e 1D), devem-se aos efeitos primários do alagamento na diminuição do crescimento radicular e da parte aérea devido à ausência de $\mathrm{O}_{2}$ no solo. Este decréscimo na alocação de biomassa em raízes alagadas pode ser observado tanto em espécies arbóreas tolerantes como para as não-tolerantes (Kozlowski, 1997; Chen et al., 2002). Mielke et al. (2003) relataram que este fato pode estar relacionado com a baixa atividade metabólica sob condições de anoxia, promovida pelo bloqueio no transporte de elétrons em nível mitocondrial. De acordo com Akilan et al. (1997), clones alagados de Eucalyptus camaldulensis formam raízes adventícias e produzem, significativamente, grande quantidade de massa seca caulinar, apresentando assim um aumento de TCRC, como foi observado no presente trabalho 
para a maioria dos clones alagados, exceto para o CP-06 (Fig. 1B).

A análise dos valores de TAL dos clones avaliados, revelou que houve decréscimos significativos $(\mathrm{P}<0,01$ e $\mathrm{P}<0,05)$ entre os tratamentos, exceto para o PS-1319 (Fig. 2A). Os valores de TAL demonstram as alterações na quantidade de biomassa formada em detrimento da energia luminosa recebida (Lucchesi, 1984) e, portanto, relaciona-se com a eficiência fotossintética da planta de modo generalizado (Ronchi et al., 2006). Logo, pode-se afirmar que a diminuição nos valores de TAL se deve ao decréscimo da taxa fotossintética promovido pelo alagamento do substrato. Os valores de AMS dos clones analisados mostraram uma tendência de diminuição entre tratamentos (Fig. 2B). A variável AMS avalia o crescimento vegetal e está relacionada à quantidade de biomassa acumulada, sendo, portanto, a produtividade primária líquida propriamente dita (Lucchesi, 1984). Qualquer estresse ambiental que prejudicar a taxa fotossintética irá afetar o ganho líquido de biomassa seca (Pereira, 1995) e, consequentemente, AMS. A redução de biomassa seca na condição de alagamento está relacionada em maior grau à diminuição das raízes preexistentes, amenizada pela formação de novas raízes adventícias (MEDRI et al., 1998).

$\mathrm{O}$ aumento de MFE verificado (Fig. 2C) pode ser atribuído a um mecanismo adaptativo de redução da área foliar em detrimento de sua biomassa, enquanto o seu decréscimo durante o crescimento indica que as folhas não se expandem às mesmas taxas, quando o crescimento progride (RICHARDS, 1969). Por outro lado, RAF representa a razão entre a área foliar e a biomassa seca total da planta (Lucchesi, 1984) e, também, pode demonstrar os efeitos do alagamento sobre a economia de carbono na planta (Blanch et al., 1999). Segundo Radford (1967), RAF tem como componentes a razão de massa foliar e a AFE. Os dois clones tolerantes ao alagamento do substrato, CCN-10 e CP-49, caracterizaram-se por apresentar baixos valores de RAF (Fig. 2D), o que, conforme Almeida e Valle (1988), teria favorecido a obtenção de altas taxas fotossintéticas.

A redução da permeabilidade de raízes, absorção de água e nutrientes minerais são algumas das respostas das plantas ao alagamento (Vartapetian e Jackson, 1997), fato também evidenciado no presente trabalho, quando se compararam as plantas alagadas aos seus respectivos controles (Figs 3 e 4). Além disso, a clorose e a epinastia foliar seguida de abscisão, induzidas pelo alagamento; associado à diversidade no padrão de absorção dos elementos minerais e sua redistribuição entre os vários órgãos vegetativos contribuíram para o decréscimo nos teores dos nutrientes minerais na planta inteira. Por outro lado, a diminuição na absorção de macro e micronutrientes minerais, acompanhada pelo decréscimo do crescimento de área foliar, promove a redução da fixação de carbono, alteração da relação fonte-dreno e diminuição do crescimento de plantas alagadas (Kozlowski, 1997; Pezeshki, 2001). Quando o sistema radicular é submetido a estresse hídrico, há um decréscimo na alocação de recursos para as folhas e caule que refletem em diminuição na fixação de carbono (Fritz et al., 2004) e, consequentemente, decréscimo na produção de energia metabólica necessária para a absorção de nutrientes. Segundo Lobo et al. (2000), para compensar a baixa produtividade energética, há uma aceleração da fermentação.

As plantas alagadas apresentaram uma série de sintomas típicos da limitação de $\mathrm{N}$, que incluem mudanças nas características alométricas e degradação dos pigmentos fotossintéticos (Ronchi et al., 2006). Conforme estes autores, o sistema radicular, provavelmente, é afetado pelo estresse e, com isso, torna-se incapaz de fornecer quantidades de $\mathrm{N}$ suficientes para suprir as necessidades para crescimento. Portanto, a deficiência de N reflete diretamente no crescimento e nas respostas fotossintéticas (Ronchi et al., 2006). Além disso, a deficiência nutricional, provocada pelo alagamento, pode ser atribuída a fatores tais como o acúmulo de substâncias tóxicas nas raízes, as quais inibem a absorção dos nutrientes minerais e causam decréscimo da disponibilidade destes elementos no solo (Ishida e Carvalho, 2002). 

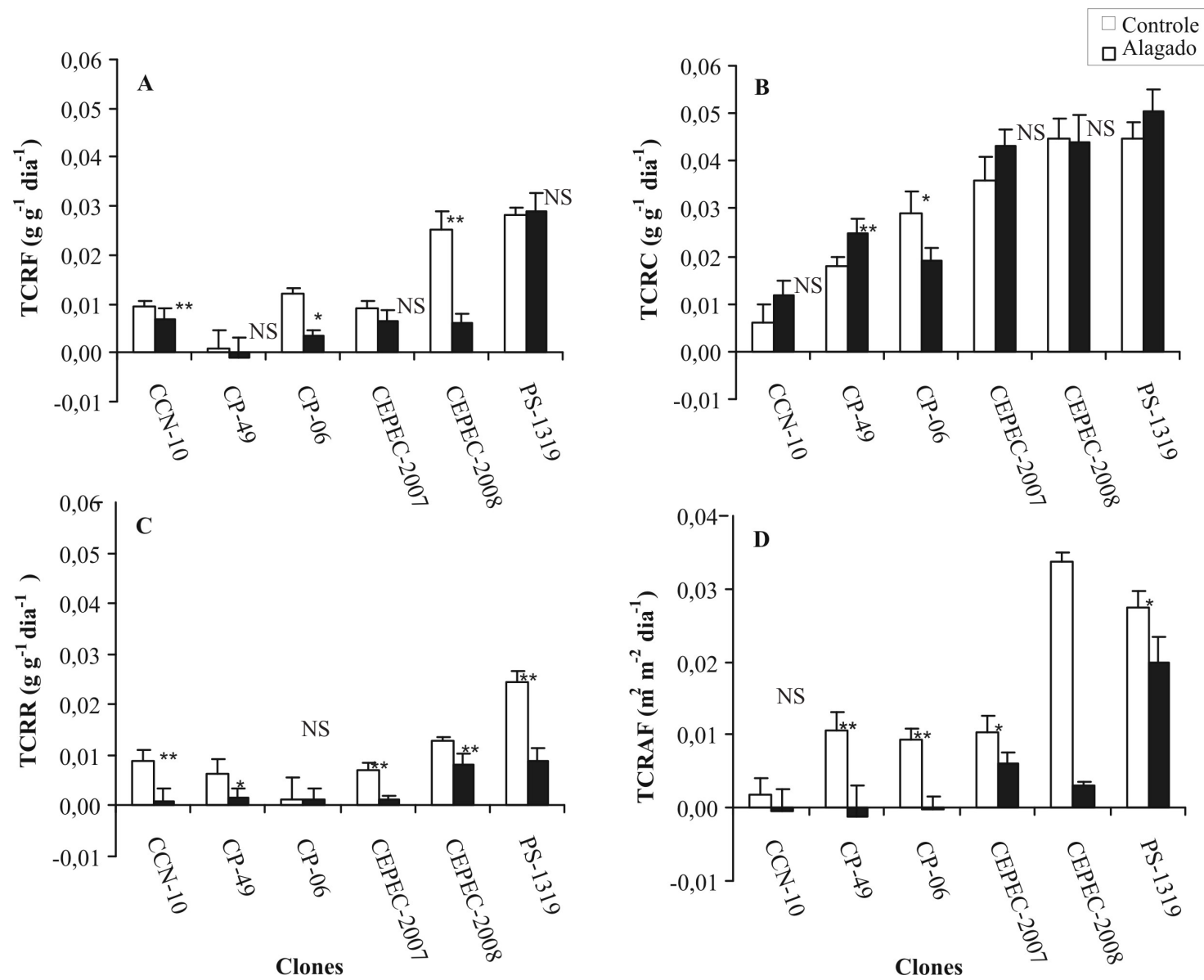

FIGURA 1 - Taxas de crescimento relativo de folha (TCRF), caule (TCRC), raiz (TCRR), de área foliar (TCRAF) de seis clones de T. cacao submetidos a alagamento do substrato por 30 dias. Valores médios de cinco repetições. $(\mathrm{T})$ Erro-padrão da média. Teste $-\mathrm{t} * *(\mathrm{P}<0,01), *(\mathrm{P}<0,05), \mathrm{NS}$ (não-significativo). 

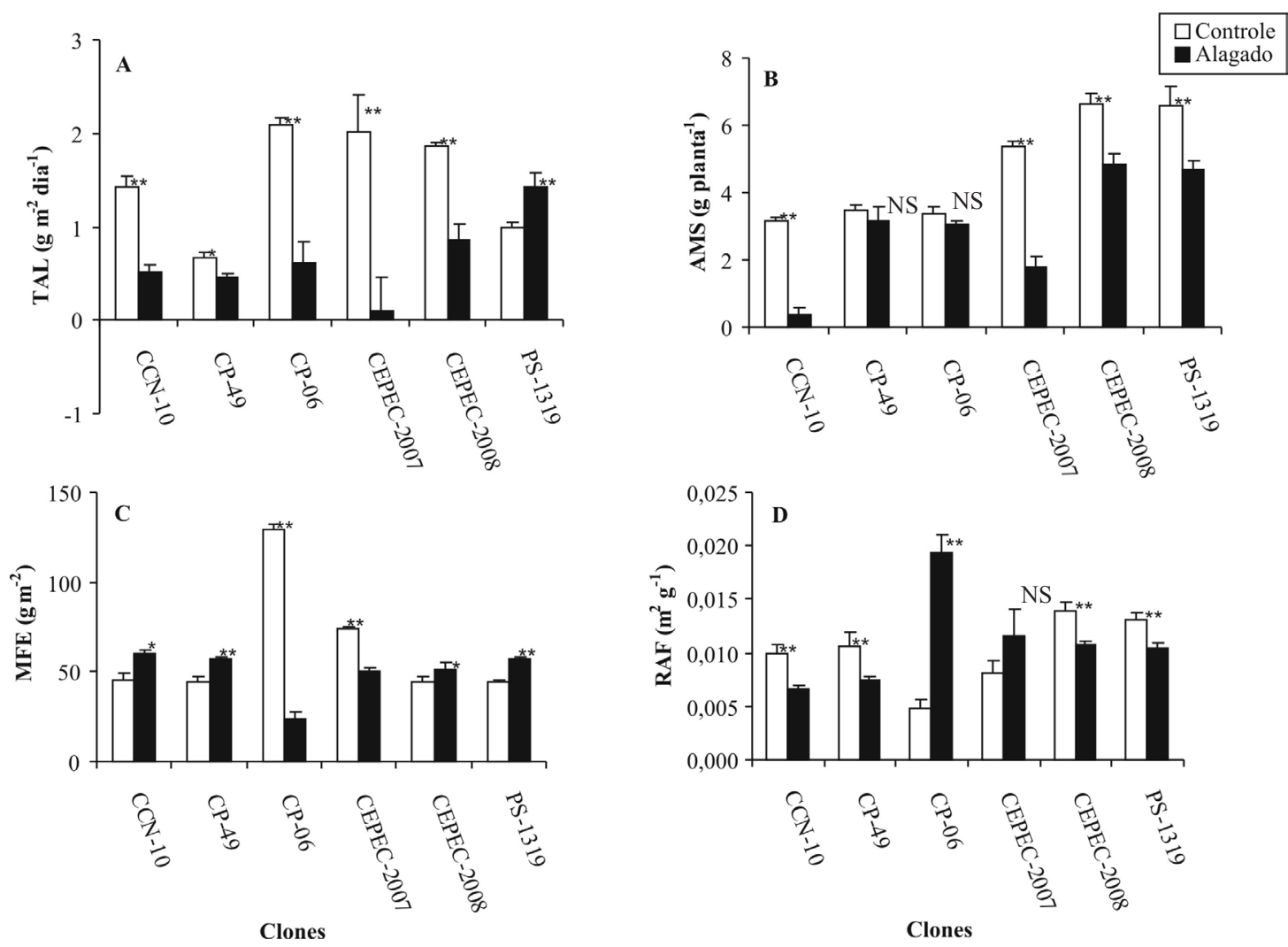

FIGURA 2- Taxa assimilatória líquida (TAL), acúmulo de matéria seca total (AMS), massa foliar específica (MFE) e razão de área foliar (RAF) de seis clones de T. cacao, aos 30 dias de alagamento do substrato. Valores médios de cinco repetições. $(T)$ Erro-padrão da média. Teste $-\mathrm{t} * *(\mathrm{P}<0,01)$, $*(\mathrm{P}<0,05)$, NS (não-significativo). 

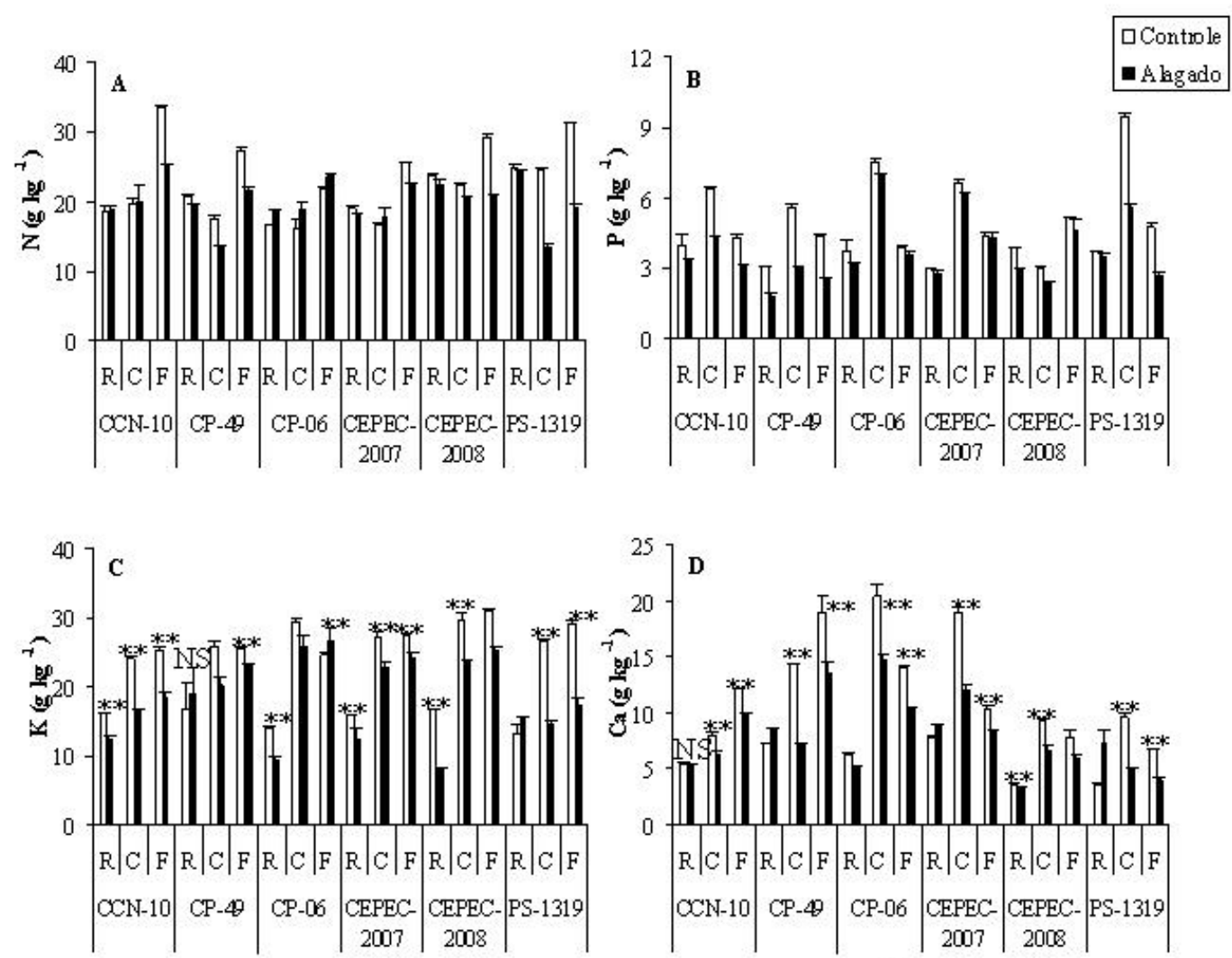

Clones

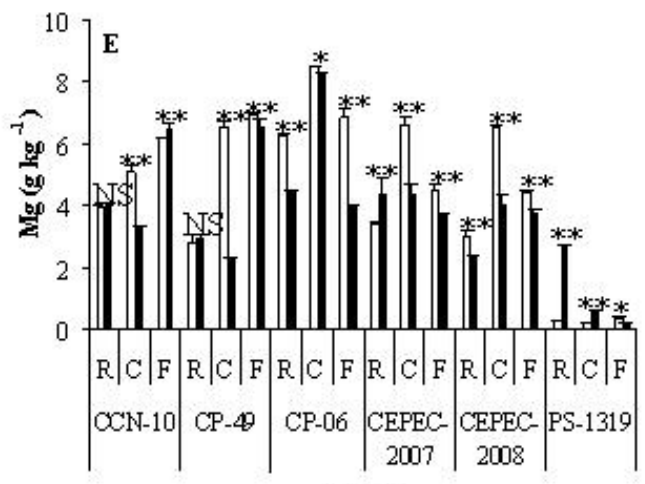

Clones

FIGURA 3 - Teores de N (A), P (B), K (C), Ca (D) e Mg (E) de órgãos vegetativos de seis clones de T. cacao submetidos ao alagamento do substrato por 30 dias. $\mathrm{R}=$ raiz; $\mathrm{C}=$ caule; $\mathrm{F}=$ folha. Valores médios de cinco repetições. ( $\mathrm{T})$ Erro-padrão da média. Teste $-\mathrm{t} * *(\mathrm{P}<0,01),{ }^{*}(\mathrm{P}<0,05), \mathrm{NS}$ (não-significativo). 

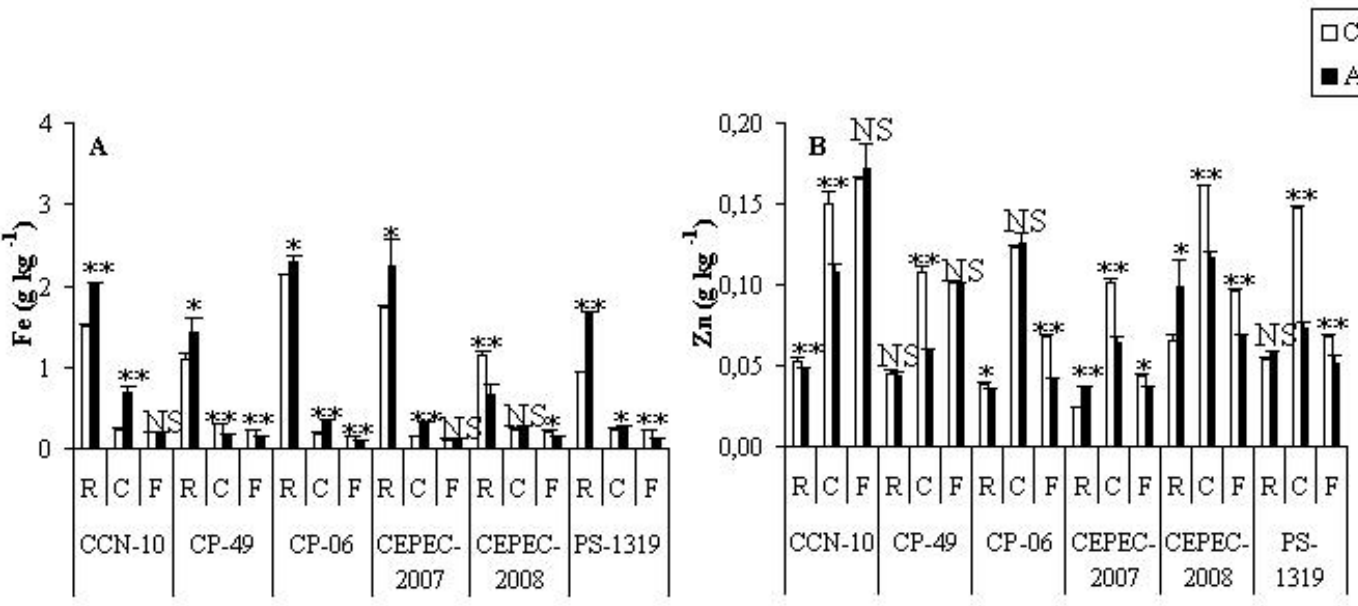

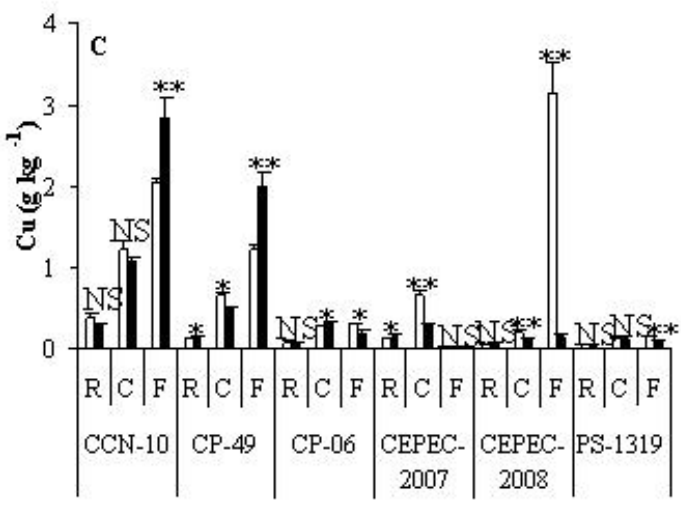

Clones

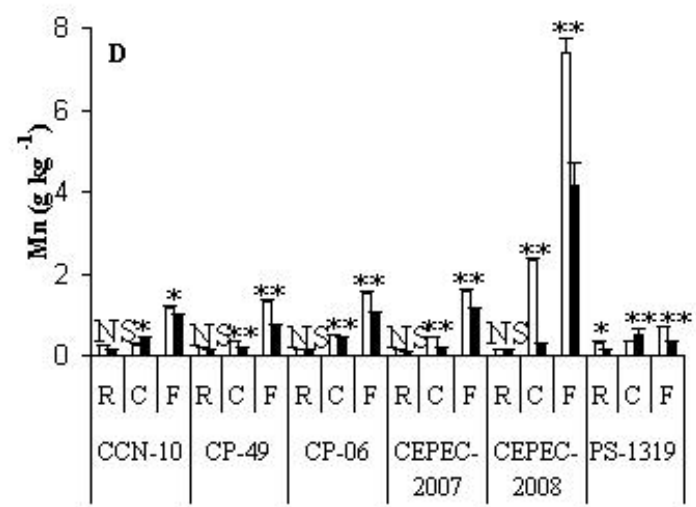

Clones

FIGURA 4 - Teores de Fe (A), Zn (B), Cu (C) e Mn (D) de órgãos vegetativos de seis clones de T. cacao submetidos a alagamento do substrato por 30 dias. $\mathrm{R}=$ raiz; $\mathrm{C}=$ caule; $\mathrm{F}=$ folha. Valores médios de cinco repetições. ( $\mathrm{T})$ Erro- padrão da média. Teste $-\mathrm{t} * *(\mathrm{P}<0,01),{ }^{*}(\mathrm{P}<0,05), \mathrm{NS}$ (não-significativo).

\section{CONCLUSÕES}

Houve uma variação interclonal em relação à tolerância ao alagamento do substrato. De acordo com as variáveis de crescimento e de composição química analisadas, verificou-se, dentre os clones avaliados, que o CP-49 foi tolerante e o CEPEC-2008 não-tolerante ao alagamento. Os demais clones ficaram numa posição intermediária. Logo, o clone CP-49 tem grande potencial para ser cultivado em condições de alagamento.

\section{AGRADECIMENTOS}

Os autores agradecem à Universidade Estadual de Santa Cruz, ao Instituto Biofábrica de Cacau, à Comissão Executiva do Plano da Lavoura Cacaueira, pelo apoio concedido; à Fundação de Amparo à Pesquisa do Estado da Bahia, pela concessão da bolsa de mestrado, e à estudante de graduação de Engenharia Agronômica Monaliza Freitas Sena, pela colaboração durante a execução do presente estudo. 


\section{REFERÊNCIAS}

AKILAN, K.;FARREL, R. C. C.; BELL, D. T.; MARSHALL, J. K. Responses of clonal river red gum (Eucalyptus camaldulensis) to waterlogging by fresh and salt water. Australian Journal of Experimental Agriculture, Collingwood, v. 37, p. 243-248, 1997.

ALMEIDA, A.A.F.; VALLE, R.R. Análise de crescimento de dez cacaueiros híbridos. Theobroma, Ilhéus, v. 18, n. 2, p. 95-113, 1988.

ALMEIDA, A-A.F.; VALLE, R.R. Ecophysiology of the cacao tree. Brazilian Journal Plant Physiology, Campinas, v. 19, p. 425-448, 2007.

BLANCH, S.J.; GANF, G.G.; WALKER, K.F. Growth and resource allocation in response to flooding in the emergent sedge Bolboschoenus medianus. Aquatic Botany, Amsterdam, v. 63, p. 145-160, 1999.

BRAGA, J.M.; DEFELIPO, B. Determinação espectrofotométrica de fósforo em extratos de solos e plantas. Revista Ceres, Viçosa, v. 21, p. $73-85,1974$.

CHEN, H.; QUALLS, R.G.; MILLER, G.C. Adaptive responses of Lepidium latifolium to soil flooding: biomass allocation, adventitious rooting, aerenchyma formation and ethylene production. Environmental and Experimental Botany, Oxford, v. 48, p. 119$128,2002$.

CHIARIELLO, N.R.; MOONEY, H.A.; WILLIANS, K. Growth, carbon allocation and cost of plant tissues. In: PEARCY, R.W.; EHLERINGER, J.R.; MOONEY, H.A.; RUNDEL, P.W. (Eds.). Plant physiological ecology: field methods and instrumentation. New York: Chapman and Hall, 1991. 327-365.

DENNIS, E.S.; DOLFERUS, R.; ELLIS, M.; RAHMAN, M.; WU, Y.; HOEREN, F.U.; GROVER, A.; ISMOND, K.P.; GOOD, A.G.; PEACOCK, W.J. Molecular strategies for improving waterlogging tolerance in plants. Journal of Experimental Botany, Oxford, v. 51, p. 89-97, 2000.
FRITZ, K.M.; EVANS, M.A.; FEMINELLA, J.W. Factors affecting biomass allocation in the riverine macrophyte Justicia Americana. Aquatic Botany, Amsterdam, v. 78, p. 279-288, 2004.

GOLTERMAN, H.L.; CLYMO, R.S.; OHNSTAD, M.A.M. Methods for physical and chemical analysis of fresh water. Oxford: Blackwell, 1978.

HUNT, R. Growth analysis: plant growth analysis for beginners. London: Unwin Hyman, 1990. p. 112 .

ISAAC, R.A.; KERBER, J.O. Atomic absorption and flame photometry: technique and uses in soil, plant and water analysis. In: WALSH, L.M. (Ed.). Instrumental methods of analysis of soils and plant tissue. Madison: Soil Science Society America, 1971. p.17-37.

ISHIDA, F.Y.; CARVALHO, C.J.R. Respostas de pupunheiras (Bactris gasipaes Kunth) jovens ao alagamento. Pesquisa Agropecuária Brasileira, Brasília, v. 37, n. 9, p. 1231-1237, 2002.

ISHIDA, F.Y.; OLIVEIRA, L.E.M.; CARVALHO, C.J.R.; ALVES, J.D. Efeitos da inundação parcial e total sobre o crescimento, teor de clorofila e fluorescência de Setaria anceps e Paspalum repens. Ciência e Agrotecnologia, Lavras, v. 26, n. 6, p. 1152-1159, 2002.

KOZLOWSKI, T.T. Responses of woody plants to flooding and salinity. Tree Physiology, Canadá, v. 1, p. 1-29, 1997.

KOZLOWSKI, T.T.; KRAMER, P.L.; PALLARDY, S.G. The physiological ecology of wood plants. San Diego: Academic Press, 1991. p. 656.

LOBO, P.C.; JOLY, C.A.. Aspectos ecofisiológicos da vesgetação de mata ciliar do Sudeste do Brasil. In: RODRIGUES, R. R.; FILHO, F. L. (Eds.). Matas ciliares conservação e recuperação. São Paulo: Edusp , 2000. p.143-157.

LUCHESI, A.A. Utilização prática da análise de crescimento vegetal. Anais da ESALQ, Piracicaba, v.41, p.181-202, 1984. 
MEDRI, M.E.; BIANCHINI, E.; PIMENTA, J.A.; DELGADO, M.F.; CORREA, G.T. Aspectos morfoanatômicos e fisiológicos de Peltophorum dubium (Spr.) Taub. submetida ao alagamento e à aplicação de etrel. Revista Brasileira de Botânica, São Paulo, v. 21, n. 3, p. 261-267, 1998.

MIELKE, M.S.; ALMEIDA, A-A.F.; GOMES, F.P.; AGUILAR, M.A.G.; MANGABEIRA, P.A.O. Leaf gas exchange, chlorophyll fluorescence and growth responses of Genipa americana seedlings to soil flooding. Environmental and Experimental Botany, Oxford, v. 50, n. 3, p. 221-231, 2003.

NÚÑEZ-ELISEA, R.; SCHAFFER, B.; FISHER, J. B.; COLLS, A. M.; CRANE, J. H. Influence of flooding on net $\mathrm{CO}_{2}$ assimilation, growth and stem anatomy of Annona species. Annals of Botany, Oxford, v. 84, p. 771-780, 1999.

PAROLIN, P. Senna reticulate, a pioneer tree from Amazonian várzea floodplains. The Botanical Review, New York, v. 67, p.239-254, 2001.

PEREIRA, J.S. Gas exchange and growth. In: SHULZE, E.D.; CALDWELL, M.M. (Eds.). Ecophysiology of photosynthesis. Berlin: SpringerVerlag, 1995. p.147-181.

PEZESHKI, S.R. Wetland plant responses to soil flooding. Environmental and Experimental Botany, Oxford, v. 46, p. 299-312, 2001.

RADFORD, R. J. Growth analysis formula their use and abuse. Crop Science, Madison, v. 7, p. 171-175, 1967.
RICHARDS, F.J. The quantitative analysis of growth. In: STEWARD, F. C. (Ed.). Plant physiology: a treatise. New York: Academic Press, 1969. 3-76.

RONCHI, C.P.; DAMATTA, F.M.; BATISTA, K.D.; MORAES, G.A.B.K.; LOUREIRO, M.E.; DUCATTI, C. Growth and photosynthetic down-regulation in Coffea arabica in response to restricted root volume. Functional Plant Biology, Collingwood, v. 33, p. 1013-1023, 2006.

SANTIAGO, E.F.; PAOLI, A.A.S. O aumento em superfície em Adelia membranifolia (Müll. Arg.) Pax \& K. Hoffm. e Peltophorum dubium (Spreng.) Taub., em resposta ao estresse por deficiência nutricional e alagamento do substrato. Revista Brasileira de Botânica, São Paulo, v. 26, n. 4, p. 503-513, 2003.

SCHAFFER, B.; ANDERSEN, P. C.; PLOETZ, R. C. Responses of fruit trees to flooding. Horticultural Reviews, New York, v. 13, p. 257-313, 1992.

SENA GOMES, A.R.; KOZLOWSKI, T.T. The effects of flooding on water relations and growth of Theobroma cacao var. catongo seedlings. Journal of Horticultural Science, Ashford Kent, v. 61, p. 265-276, 1986.

SOUZA JÚNIOR, J.O. Substratos e adubação para mudas clonais de cacaueiro. 2007. Tese (Doutorado) - Escola Superior de Agricultura "Luiz de Queiroz", Universidade de São Paulo, Piracaiba, 2007.

VARTAPETIAN, B. B.; JACKSON, M. B. Plant adaptations to anaerobic stress. Annals of Botany, London, v. 79, p. 3-20, 1997. 